\title{
Rapid assessment of bat diversity in the Taita Hills Afromontane cloud forests, southeastern Kenya
}

\author{
Adrià López-Baucells ${ }^{1,2, *,+}$, Ricardo Rocha ${ }^{2,3,4, *}$, Paul Webala $^{5}$, Abhilash Nair $^{3}$, \\ Ruut Uusitalo ${ }^{6}$, Tarja Sironen ${ }^{6}$, Kristian M. Forbes $^{6}$
}

\author{
${ }^{1}$ Granollers Museum of Natural Sciences, 08402 Granollers, Catalonia (Spain) \\ ${ }^{2}$ Center for Ecology, Evolution and Environmental Changes (cE3c), \\ Faculdade de Ciências da Universidade de Lisboa, 1749-016 Lisboa (Portugal) \\ ${ }^{3}$ Metapopulation Research Centre, Faculty of Biosciences, University of Helsinki, FI-00014 Helsinki (Finland) \\ ${ }^{4}$ Faculty of Life Sciences University of Madeira, 9000-082, Funchal (Portugal) \\ ${ }^{5}$ Department of Forestry and Wildlife Management, Maasai Mara University, P.O. Box 861, 20500 Narok (Kenya) \\ ${ }^{6}$ Department of Virology, Faculty of Medicine, University of Helsinki, FI-00290 Helsinki (Finland) \\ ${ }^{*}$ Both authors have contributed equally \\ +Corresponding author: Adrià López-Baucells (adria.baucells@gmail.com)
}

DOI: https://doi.org/10.14709/BarbJ.9.1.2016.04

Spanish title: Rápida evaluación de la diversidad de murciélagos en los bosques nebulosos de las montañas Afromontanas de Taita, sureste de Kenya.

\begin{abstract}
Tropical mountain ranges are known to support high biodiversity. In addition to their role as refuge habitat, complex topography within these ecosystems promotes the development of diverse species traits and evolutionary divergence. However, species within these environments also face severe anthropological threats, most notably from habitat loss and degradation, invasive species, and climate change. A primary example is the Taita Hills in Kenya, which forms the northernmost portion of the biodiversity rich Eastern Arc Mountains. Despite the high biodiversity potential for the area, little is known regarding chiropteran diversity. In order to address this lack of knowledge, we conducted a rapid biological survey of bats during January-February 2016. Our trapping effort was focused on different habitat types (e.g. highland cloud rainforest fragments, lowland riverbeds and human structures) and diverse trapping methods were used (e.g. mist-netting and hand-netting). A total of 169 bats belonging to at least 19 species from 7 different families were captured across 16 sampling sites. We report 10 new species records for the Taita Hills region, including the first record of Miniopterus mossambicus for East Africa, with a major range expansion in its distribution, as well as the first echolocation call for Glauconycteris argentata in eastern Africa. Several cases of probable species complexes were also identified, which are the focus of ongoing molecular work. Together, our results demonstrate that the Taita Hills region is home to rich bat diversity, not yet completely assessed, and emphasizes the urgent need to conserve the remaining forest fragments.
\end{abstract}

Keywords: Miniopterus mossambicus, Afrotropical mountains, biodiversity, Chiroptera, Cyt-b mtDNA, DNA barcoding, Glauconycteris argentata. 


\section{INTRODUCTION}

Tropical mountain ranges can act as hotspots for biological diversity (Fjeldså et al. 1997, Badgley et al. 2017). In addition to their role as refuge, the diverse climatic conditions and habitat heterogeneity within these ecosystems promotes the development of diverse species traits (Presley et al. 2012, Cisneros et al. 2014, Chaverri et al. 2016, Peters et al. 2016, Badgley et al. 2017). This, combined with restricted genetic exchange across elevational gradients, drives evolutionary divergence and endemism (e.g. Crochet et al. 2004). In essence, mountain tops represent 'sky islands' and the biodiversity of these areas suffers from many of the threats that occur on conventional islands. These range from habitat loss and degradation, to the impacts of invasive species, and the negative consequences of climate change (Millennium Ecosystem Assessment 2005, Malcolm et al. 2006, Guo et al. 2013, Le Saout et al. 2013). Together these factors render tropical mountain ecosystems a high priority for research and conservation action.

East Africa is well known for its diverse mammalian fauna. The region's bat fauna ranks amongst the most diverse globally, and with 108 recorded species to date, Kenya is second only to the Democratic Republic of Congo in terms of African chiropteran diversity (Patterson and Webala 2012). Together with other mountains of the Eastern Arc, the Taita Hills form the Eastern Afromontane (EAM) biodiversity hotspot (Mittermeier et al. 2004) and are home to a high number of endemic plant and animal species (Brooks et al. 1998, Myers et al. 2000, Wagura 2014). This high level of endemism is reflective of the EAM age (290-180 Myr BP) and isolation, combined with long periods of climatic stability (Thijs et al. 2014). Like other mountain regions across the EAM, the Taita Hills have previously and continue to experience high levels of anthropogenic pressure (Pellikka et al. 2009). Around 95\% of the Taita Hills original forest area has been cleared over the past 250 years (Newmark 2002), with approximately 50\% lost between 1955 and 2004 alone (Pellikka et al. 2009). The remaining forest is heavily fragmented, as human pressure and encroachment have degraded many of the smallest forest patches. The remnant forest fragments range from 180 ha (Mbololo) to 1 ha (Vuria, Kichuchenyi and Ronge) and are all located $1300 \mathrm{~m}$ above sea level (Thijs et al. 2014).

Very little is known regarding bat diversity in the Taita Hills, beyond two publications for the region, published in 2005 and 2014, which list bat inventory (Taylor et al. 2005, Wagura 2014). The most recent of these is a general field guide of the area, for which the sources and timing of bat records are not reported. Given the ongoing threats facing the biodiversity rich Taita Hills ecosystem, particularly in the form of habitat loss, the purpose of this study was to update the poorly documented bat fauna in the region through a rapid biological survey of bats.

\section{Material And Methods}

\section{STUDY AREA}

The Afromontane cloud forests of the Taita Hills are located in southeastern Kenya ( $\left.3^{\circ} 20^{\prime} \mathrm{S}, 38^{\circ} 15^{\prime} \mathrm{E}\right), 360 \mathrm{~km}$ southeast of the capital Nairobi and $190 \mathrm{~km}$ northwest of another major city, Mombasa, and form the northernmost portion of the Eastern Arc Mountains. The $1000 \mathrm{~km}^{2}$ stretch is characterized by complex topographical variations and marked vegetation gradients, ranging from dry semi-arid savannas and grassland (600-700 $\mathrm{m}$ above sea level), to steep mountain slopes that culminate in Vuria peak at $2208 \mathrm{~m}$ (Thijs et al. 2014). The Taita Hills comprise four main hills: Dawida (2228 m), Mt. Mbololo (1779 m), Sagalla Hill (1500 $\mathrm{m})$ and Mt. Kasigau (1645 m), surrounded by the Voi River and the Tsavo plains at 600-700 m elevation.

The climate is tropical, with two distinct bimodal rain seasons, one from November to December and another from March to May. Mean annual temperature decreases $\left(22^{\circ}\right.$ to 16 $\left.{ }^{\circ} \mathrm{C}\right)$ with increasing altitude whereas rainfall increases (600 to $1400 \mathrm{~mm}$ ) from the lowlands to the hilltops (Jaetzold and Schmidt 1983). The moist forest on the hilltops is dependent on precipitation from trapped moisture transported by the southeast winds originating from the Indian Ocean (Thijs et al. 2014). The vegetation on the hills consists of different types of short dry bushland that encircle a diverse mosaic of moist-forest fragments and smallholder crops and plantations. Plantations (both autochthonous and exotic) are also on the slopes, usually next to more populated valleys. Human populations in the region have grown by an annual average of $1.8 \%$ over previous decades, reaching 246,671 inhabitants in 1999 (average of 534 persons $/ \mathrm{km}^{2}$ ) (Republic of Kenya 2001, Pellikka et al. 2009). Villages tends to be located close to water sources as local communities are highly dependent on small agriculture and forestry.

\section{BAT SURVEYS}

Bats surveys were conducted over a two-week period in early 2016 as part of an infectious disease-research expedition led by the University of Helsinki (January 28 to February 8). Sampling sites were selected based on local knowledge of bat roosts and their accessibility, and to incorporate different habitat types: villages $(n=4)$, primary forest fragments, $(n=2)$, savannah $(n=4)$, ponds embedded in agricultural areas $(n=4)$, exotic forest plantation $(n=1)$ and cave $(n=1)$ (Table 1; Fig. 1, 2 and 3). Several trapping methodologies were employed to promote species diversity in the captured bats [mist-netting, hand-netting in roosts (both in caves and human structures) and acoustic surveys]. Most bats were captured using ground-level mist-nets $(3 \times 2.5$ to $12 \times 2.5 \mathrm{~m}$ ECOTONE, Poland), with 5-9 nets set at each sampling location per night. Trapping was performed nightly and nets were opened from dusk for up to 6 hours. Some bats, particularly in villages and caves, were captured using hand-nets. Bat species identification followed Patterson and Webala (2012) and Monadjem et al. (2010), and taxonomy follows Simmons (2005). Captured individuals were kept in cotton bags prior to processing, and standard measurements (forearm length and weight), and sex and reproductive status were then recorded. A wing tissue sample $(2 \mathrm{~mm}$, Stiefel Laboratories, Inc., Germany) was collected from all bats for 

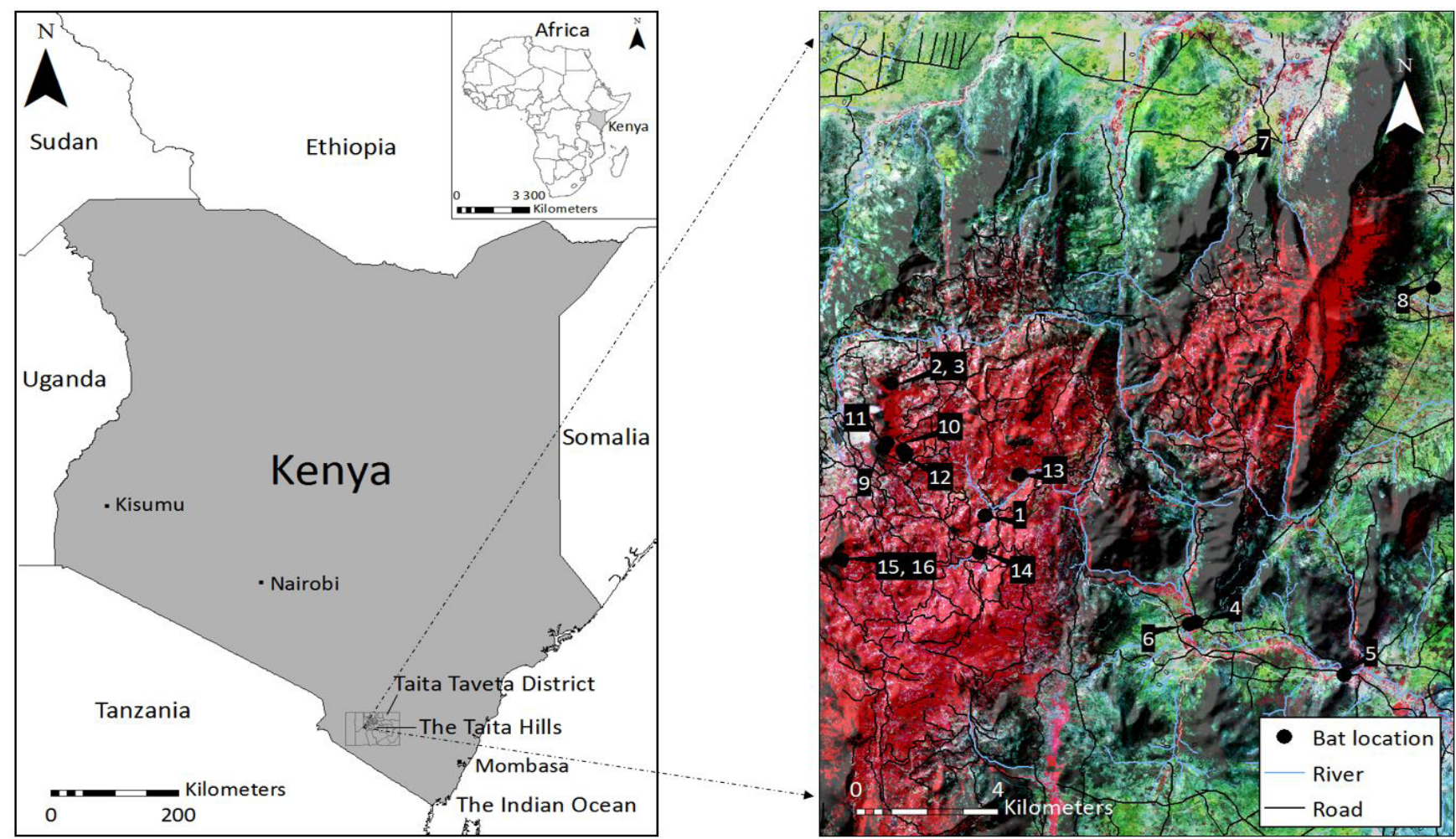

Fig. 1 - Map depicting the Taita Hills in southeastern Kenya, and the specific trapping locations therein (Sentinel-2A false colour image).
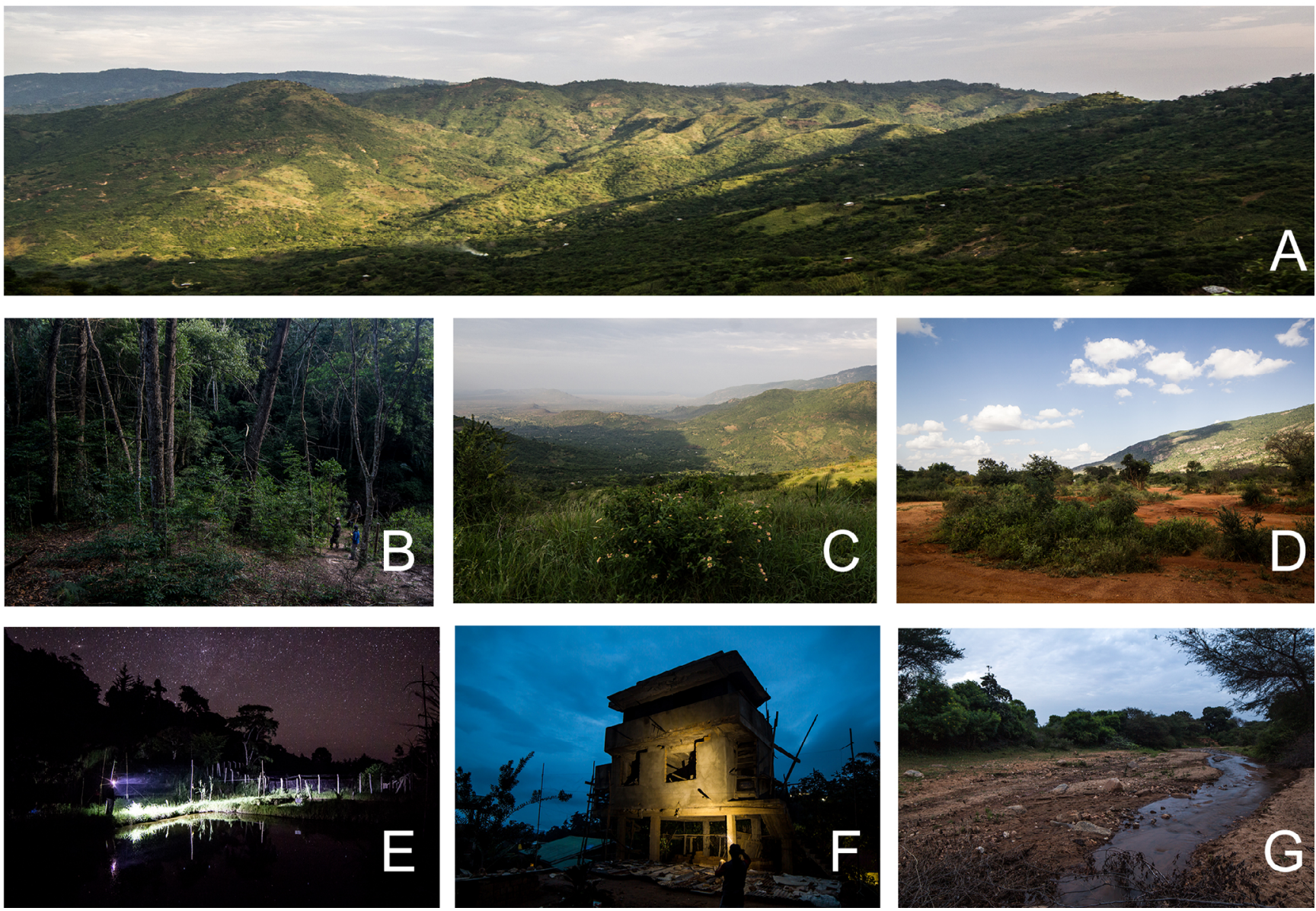

Fig. 2 - Habitats sampled during the rapid bat biodiversity assessment in the Taita Hills. A) mountain range in Taita Hills, B) moist-forest fragment on hilltop, C) bushlands, D) lowlands and savannah, E) fish ponds embedded in agricultural area in highlands, F) village roost, G) Voi River. 
molecular analyses. One voucher for the following species were collected and deposited at the Mammalogy Section of the National Museum of Kenya: Glauconycteris argentata, Pipistrellus hesperidus, Miniopterus sp., Rhinolophus clivosus and Nycticeinops schieffeni.

Field identifications were complemented by DNA barcoding of uncertain species. DNA material was extracted from wing punches using a NucleoSpin ${ }^{\circledR}$ Tissue kit (Macherey-Nagel) and following the manufacturer guidelines. The cytochrome $b$ gene (Cyt-b) was sequenced for species identification, one of the most commonly used (mitochondrial) molecular marker in bat fauna (Hamilton et al. 2015). The primers employed were L15146 (5'-CATGAGGACAAATATCATTCTGAG-3') and H15915 (5'-TCTCCATTTCTGGTTTACAAG AC-3') (Irwin et al. 1991), and polymerase chain reactions were done using protocols described by Lamb et al. (2012). The sequences were compared with those available in GenBank. Sequences acquired during this study are deposited in GenBank (see accession numbers in the Supplementary material, Table 1).

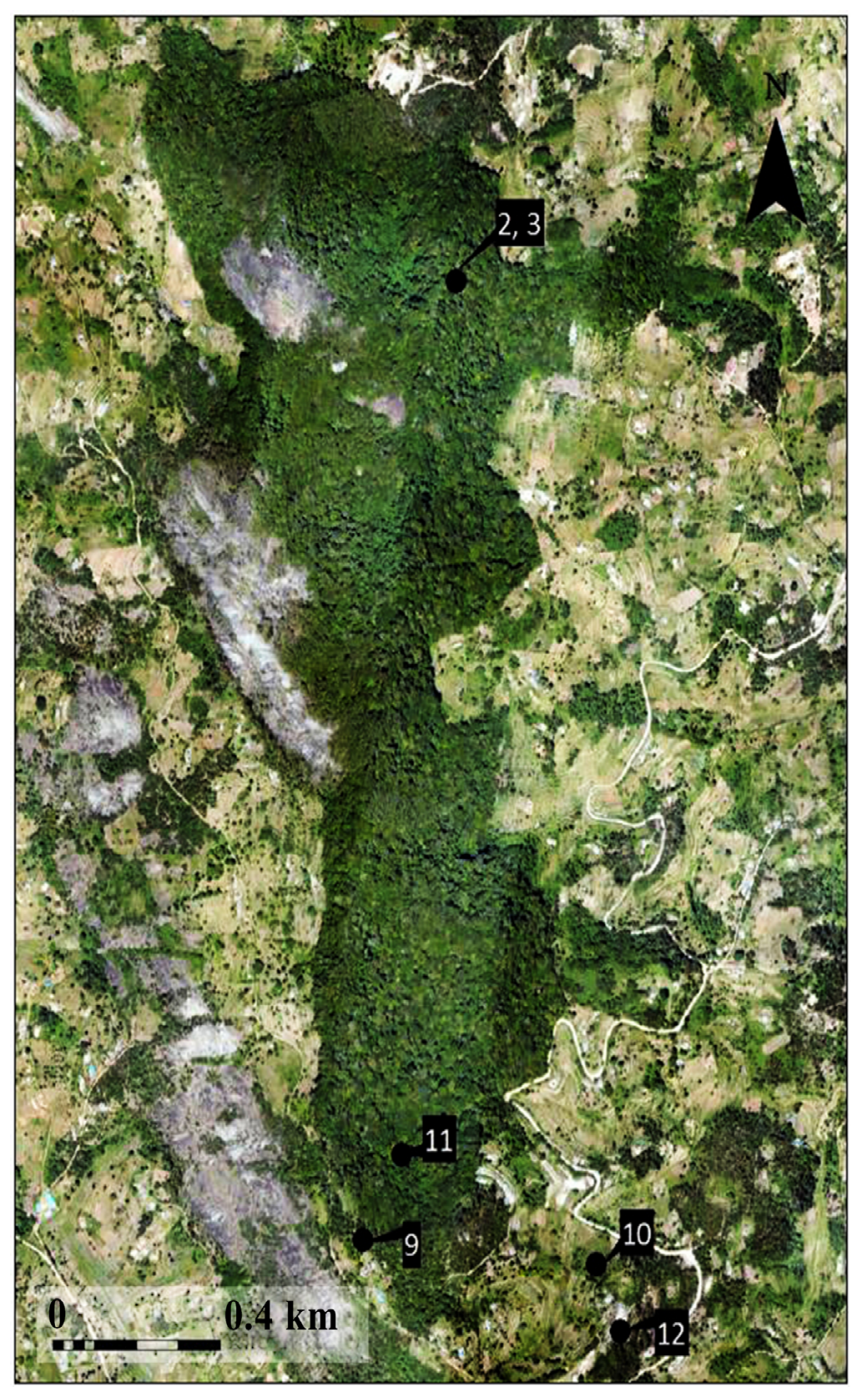

Fig. 3 - Aerial view of Ngangao fragment. A true- colour aerial image mosaic from 2012 acquired by Department of Geography, University of Helsinki.

\section{ECHOLOCATION RECORDINGS}

For almost all species we recorded release calls to compile a reference library for the region. Echolocation calls were recorded simultaneously using two Pettersson D1000X detectors (Pettersson Elektronik AB, Uppsala, Sweden). The detectors were placed $10-20 \mathrm{~m}$ from the release point (depending on the species). Upon release, bats use highly modulated pulses that gradually came back to normal shapes. Normalized pulses were selected for reporting (Britzke et al. 2011). Most species were released by hand at ground level. However, species with poor manoeuvrability in cluttered spaces, such as molossids (Voigt and Holderied 2012), were released from higher elevations close to the capture site. Recordings were made at a sampling frequency of $250 \mathrm{kHz}$, with 16 bits/sample.

For sound analysis, a customized 512 point fast Fourier transform (FFT) was used with a Hanning window for both spectrograms and power spectrum. To characterize the echolocation calls, peak frequency or frequency with maximum energy (FME), start frequency (St-freq) and end frequency (End-freq) (Jung et al. 2014, López-Baucells et al. 2016), were measured using Kaleidoscope v.3.1.4b (Wildlife Acoustics, USA). Other common measurements, such as bandwidth and pulse duration, were not considered as these are unreliable following hand release (López-Baucells et al. unpublished data). To minimize measurement error, only pulses with echolocation calls $20 \mathrm{~dB}$ above the background noise were measured. In this study, we only provide information for the rare species, Glauconycteris argentata, due to a prior lack of reference calls in the literature.

\section{RESULTS}

Across 16 sites (Fig. 1, Table 1), we captured a total of 169 bats comprising 19 species belonging to seven families: Vespertilionidae (8), Pteropodidae (3), Molossidae (3), Rhinolophidae (2), Miniopteridae (2), Megadermatidae (1) and Hipposideridae (1) (Fig. 4 and Table 2). With these data, we provide the first report of Miniopterus mossambicus for East Africa, confirm eight previously reported species by Taylor et al. (2005) and three by Wagura (2014), and update the Taita Hills chiropteran inventory with 10 new bat species records.

We identified two cryptic species previously unreported for the area (Pipistrellus hesperidus and Neoromicia spp), one species with a heavily fragmented distribution (Rhinolophus clivosus), and another species only recently described to science that is still absent from field guides (Miniopterus mossambicus; Monadjem et al. 2013) (Table 3). For some species that were confidently identified in the field by their well-known diagnostic morphological characters, we found low similarity values for matching DNA sequences in GenBank (Hipposideros caffer and Myotis tricolor with 9596\%; Table 2), while for Glauconycteris argentata no Cyt-b reference sequences were available. As such, our sequence represents the first submission to GenBank for this species. The closest match was Glauconycteris variegata, with $84 \%$ sequence similarity. However, these species are clearly differentiated by wing coloration (Patterson and Webala 2012). 
Table 1 - Characteristics of the 16 bat trapping sites in the Taita Hills, as located in Figure 1.

\begin{tabular}{|c|c|c|c|c|c|}
\hline \# & Trapping site & Latitude & Longitude & Elevation (m) & Habitat \\
\hline 1 & Kambito & $03^{\circ} 23 ' 25.1$ 'S & $38^{\circ} 21^{\prime} 57.8^{\prime \prime} \mathrm{E}$ & 1285 & Cave \\
\hline 2 & Kitumbi & $03^{\circ} 21^{\prime} 14.1 ” S$ & $38^{\circ} 20^{\prime} 32.7^{\prime \prime} \mathrm{E}$ & 1791 & Exotic forest \\
\hline 3 & Kitumbi & $03^{\circ} 21^{\prime} 14.1^{\prime \prime S}$ & $38^{\circ} 20^{\prime} 32.7^{\prime \prime} \mathrm{E}$ & 1791 & Pond \\
\hline 4 & Msao 1 & $03^{\circ} 25^{\prime} 11.0^{\prime \prime} \mathrm{S}$ & $38^{\circ} 25^{\prime} 9.59^{\prime \prime} \mathrm{E}$ & 683 & Partly dry river bed / savannah \\
\hline 5 & Msao 2 & $03^{\circ} 26^{\prime} 3.59^{\prime \prime} \mathrm{S}$ & $38^{\circ} 27^{\prime} 24.0^{\prime \prime} \mathrm{E}$ & 650 & Partly dry river bed / savannah \\
\hline 6 & Msao 3 & $03^{\circ} 25^{\prime} 13.1^{\prime \prime S}$ & $38^{\circ} 25^{\prime} 3.58^{\prime \prime} \mathrm{E}$ & 680 & Partly dry river bed / savannah \\
\hline 7 & Mwakajho & $03^{\circ} 17^{\prime} 29.4^{\prime \prime} \mathrm{S}$ & $38^{\circ} 25^{\prime} 42.1^{\prime \prime} \mathrm{E}$ & 714 & Dry river bed/ savannah \\
\hline 8 & Mwandau Voi & 03॰19'39.2”S & $38^{\circ} 28^{\prime} 45.6^{\prime \prime} \mathrm{E}$ & 718 & Village \\
\hline 9 & Ngangao fish ponds & $03^{\circ} 22^{\prime} 24.5^{\prime \prime} \mathrm{S}$ & $38^{\circ} 20^{\prime} 45.4^{\prime \prime} \mathrm{E}$ & 1702 & Pond \\
\hline 10 & Ngangao fragment & $03^{\circ} 16^{\prime} 48.8^{\prime \prime S}$ & $38^{\circ} 26^{\prime} 13.7 ’ \mathrm{E}$ & 1857 & Primary forest fragment \\
\hline 11 & Ngangao plantation & $03^{\circ} 22^{\prime} 18.3^{\prime \prime S}$ & $38^{\circ} 20^{\prime} 25.4^{\prime \prime} \mathrm{E}$ & 1818 & Plantation \\
\hline 12 & Ngangao pond & $03^{\circ} 22^{\prime} 20.0^{\prime \prime} \mathrm{S}$ & $38^{\circ} 20^{\prime} 43.5^{\prime \prime} \mathrm{E}$ & 1681 & Pond \\
\hline 13 & Private house & $03^{\circ} 22^{\prime} 44.2^{\prime \prime} \mathrm{S}$ & $38^{\circ} 22^{\prime} 29.3 ’ \mathrm{E}$ & 1568 & Village - inhabited house \\
\hline 14 & Taita Research Station & $03^{\circ} 24^{\prime} 2.05^{\prime \prime} \mathrm{S}$ & $38^{\circ} 21^{\prime} 52.6^{\prime \prime} \mathrm{E}$ & 1395 & Village \\
\hline 14 & Taita Station - Inhabited house & $03^{\circ} 24^{\prime} 2.05^{\prime \prime} \mathrm{S}$ & $38^{\circ} 21^{\prime} 52.6^{\prime \prime} \mathrm{E}$ & 1395 & Village \\
\hline 15 & Yale fragment & $03^{\circ} 24^{\prime} 8.86^{\prime \prime S}$ & $38^{\circ} 19^{\prime} 47.3^{\prime \prime} \mathrm{E}$ & 1568 & Primary forest fragment \\
\hline 16 & Yale pond & $03^{\circ} 24^{\prime} 8.86^{\prime \prime} \mathrm{S}$ & $38^{\circ} 19^{\prime} 47.3^{\prime \prime} \mathrm{E}$ & 1568 & Pond \\
\hline
\end{tabular}

Table 2 - Best matching mitochondrial sequences (Cyt-b) in GenBank for bats with uncertain field identification.

\begin{tabular}{llll}
\hline Species & GenBank sp & Identity (\%) & Matching GenBank ID \\
\hline Glauconycteris argentata & Glauconycteris variegata & $84 \%$ & JX276108.1 \\
\hline Hipposideros caffer & Hipposideros caffer & $95 \%$ & EU934457.1 \\
\hline Miniopterus sp. & Miniopterus mossambicus & $99 \%$ & KF709538.1 \\
\hline Miniopterus sp. & Miniopterus minor & $97 \%$ & FJ232804.1 \\
\hline Miniopterus sp. & Miniopterus schreibersii natalensis & $91 \%$ & AJ841977.1 \\
\hline Miniopterus sp. & Miniopterus schreibersii natalensis & $91 \%$ & JX276239.1 \\
\hline Myotis tricolor & Myotis tricolor & $96 \%$ & AJ841953.1 \\
\hline Pipistrellus cf. hesperidus & Pipistrellus hesperidus & $99 \%$ & KM886090.1 \\
\hline Pipistrellus cf. hesperidus & Pipistrellus hesperidus & $99 \%$ & KM886090.1 \\
\hline Pipistrellus cf. hesperidus & Pipistrellus hesperidus & $99 \%$ & KM886090.1 \\
\hline Pipistrellus sp & Neoromicia nanus haplotype Namibia & $99 \%$ & KX375180.1 \\
\hline Pipistrellus sp & Neoromicia nanus haplotype Namibia & $99 \%$ & KX375180.1 \\
\hline Pipistrellus sp & Neoromicia nanus & $95 \%$ & JX276203.1 \\
\hline Pipistrellus sp. & Neoromicia zuluensis & $93 \%$ & KX375186.1 \\
\cline { 2 - 4 } & Neoromicia somalicus & $91 \%$ & AJ841977.1 \\
\hline Rhinolophus sp. & Rhinolophus clivosus & $100 \%$ & EU436674.1 \\
\hline Rhinolophus sp. & Rhinolophus clivosus & $100 \%$ & EU436674.1 \\
\hline Scotoecus hirundo & Pipistrellus hesperidus & $86 \%$ & JX276313.1 \\
\hline Scotoecus hirundo & Pipistrellus hesperidus & $86 \%$ & JX276313.1 \\
\hline Scotoecus hirundo & Pipistrellus hesperidus & $86 \%$ & JX276313.1 \\
\hline Scotoecus hirundo & Pipistrellus hesperidus & $86 \%$ & JX276313.1 \\
\hline Scotoecus hirundo & Pipistrellus hesperidus & $86 \%$ & JX276313.1 \\
\hline Scotophilus dinganii & Scotophilus viridis & $98 \%$ & EU750986.1 \\
\cline { 2 - 4 } Scotophilus dinganii & Scotophilus dinganii & $96 \%$ & EU750993.1 \\
\hline & Scotophilus viridis & $98 \%$ & EU750986.1 \\
\cline { 2 - 4 } & Scotophilus dinganii & EU750993.1 \\
\hline
\end{tabular}


Table 3- Checklist of bat species from our Taita Hills survey, southeastern Kenya, in comparison to previous reports in the same area.

\begin{tabular}{|c|c|c|c|c|c|c|c|}
\hline & Species $^{1}$ & Taylor et al. 2005 & Wagura 2014 & Current project & English name $^{1}$ & IUCN threat level $^{2}$ & Habitats where detected $^{3}$ \\
\hline \multirow{3}{*}{ Pteropodidae } & Epomophorus wahlbergi & $\checkmark$ & $\checkmark$ & $\checkmark$ & Wahlberg's Epauletted Fruit Bat & Least concern & $\mathrm{A}, \mathrm{B}, \mathrm{C}, \mathrm{D}$ \\
\hline & Lissonycteris angolensis & & & $\checkmark$ & Angolan Fruit Bat & Least concern & $\mathrm{B}, \mathrm{D}$ \\
\hline & Rousettus aegyptiacus & & $\checkmark$ & $\checkmark$ & Egyptian Fruit Bat & Least concern & A, B, C, D \\
\hline \multirow{4}{*}{ Rhinolophidae } & Rhinolophus clivosus & & & $\checkmark$ & Geoffroy's Horseshoe Bat & Least concern & A, B \\
\hline & Rhinolophus darlingi & & $\checkmark$ & & Darling's Horseshoe Bat & Least concern & \\
\hline & Rhinolophus hildebrandtii & $\checkmark$ & $\checkmark$ & & Hildebrandt's Horseshoe Bat & Least concern & \\
\hline & Rhinolophus landeri & $\checkmark$ & & $\checkmark$ & Lander's Horseshoe Bat & Least concern & A, B \\
\hline \multirow{2}{*}{ Hipposideridae } & Hipposideros caffer & $\checkmark$ & & $\checkmark$ & Sundevall's Roundleaf Bat & Least concern & A \\
\hline & Triaenops afer & $\checkmark$ & & & Persian Trident Bat & Least concern & \\
\hline \multirow{2}{*}{ Megadermatidae } & Cardioderma cor & $\checkmark$ & & $\checkmark$ & Heart-nosed Bat & Least concern & $\mathrm{A}, \mathrm{C}$ \\
\hline & Lavia frons & $\checkmark$ & & & Yellow-winged Bat & Least concern & \\
\hline Emballonuridae & Coleura afra & $\checkmark$ & & & African Sheath-tailed Bat & Least concern & \\
\hline Nycteridae & Nycteris thebaica & $\checkmark$ & & & Cape Long-eared Bat & Least concern & \\
\hline \multirow{6}{*}{ Molossidae } & Chaerephon major & & & $\checkmark$ & Large Wrinkle-lipped Bat & Least concern & $\mathrm{A}$ \\
\hline & Chaerephon pumilus & $\checkmark$ & & $\checkmark$ & Little Free-tailed Bat & Least concern & $\mathrm{C}$ \\
\hline & Mops midas & & $\checkmark$ & & Midas Free-tailed Bat & Least concern & \\
\hline & Otomops harrisoni & $\checkmark$ & & & Large-eared Free-tailed Bat & Near threatened & \\
\hline & Tadarida aegyptiaca & & & $\checkmark$ & Egyptian Free-tailed Bat & Least concern & A \\
\hline & Tadarida ventralis & $\checkmark$ & $\checkmark$ & & Giant free-tailed Bat & Data deficient & \\
\hline \multirow{2}{*}{ Miniopteridae } & Miniopterus mossambicus & & & $\checkmark$ & Mozambican Long-fingered Bat & Not yet assessed & $\mathrm{C}$ \\
\hline & Miniopterus sp. & & & $\checkmark$ & Long-fingered Bat & & C, D \\
\hline \multirow{9}{*}{ Vespertilionidae } & Glauconycteris argentata & & & $\checkmark$ & Silvered Bat & Least concern & $\mathrm{C}, \mathrm{D}$ \\
\hline & Myotis tricolor & & & $\checkmark$ & Temminck's Mouse-eared Bat & Least concern & $\mathrm{B}$ \\
\hline & Neoromicia capensis & & $\checkmark$ & & Cape Pipistrelle & Least concern & \\
\hline & Neoromicia nana & & $\checkmark$ & $\checkmark$ & Banana Pipistrelle & Least concern & $\mathrm{B}, \mathrm{C}$ \\
\hline & Neoromicia sp. & $\checkmark$ & & $\checkmark$ & & & C, D \\
\hline & Nycticeinops schlieffeni & & & $\checkmark$ & Schlieffen's Bat & Least concern & $\mathrm{C}$ \\
\hline & Pipistrellus hesperidus. & & & $\checkmark$ & African Pipistrelle & Least concern & $\mathrm{B}, \mathrm{C}, \mathrm{D}$ \\
\hline & Scotoecus hirundo & $\checkmark$ & $\checkmark$ & $\checkmark$ & Lesser House Bat & Least concern & $\mathrm{A}, \mathrm{C}$ \\
\hline & Scotophilus dinganii & $\checkmark$ & & $\checkmark$ & Yellow bellied House Bat & Least concern & $\mathrm{C}$ \\
\hline
\end{tabular}

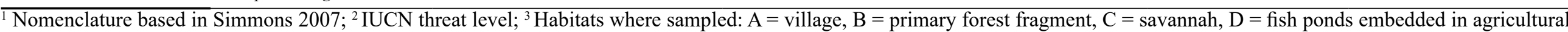
area, $\mathrm{E}=$ cave . 

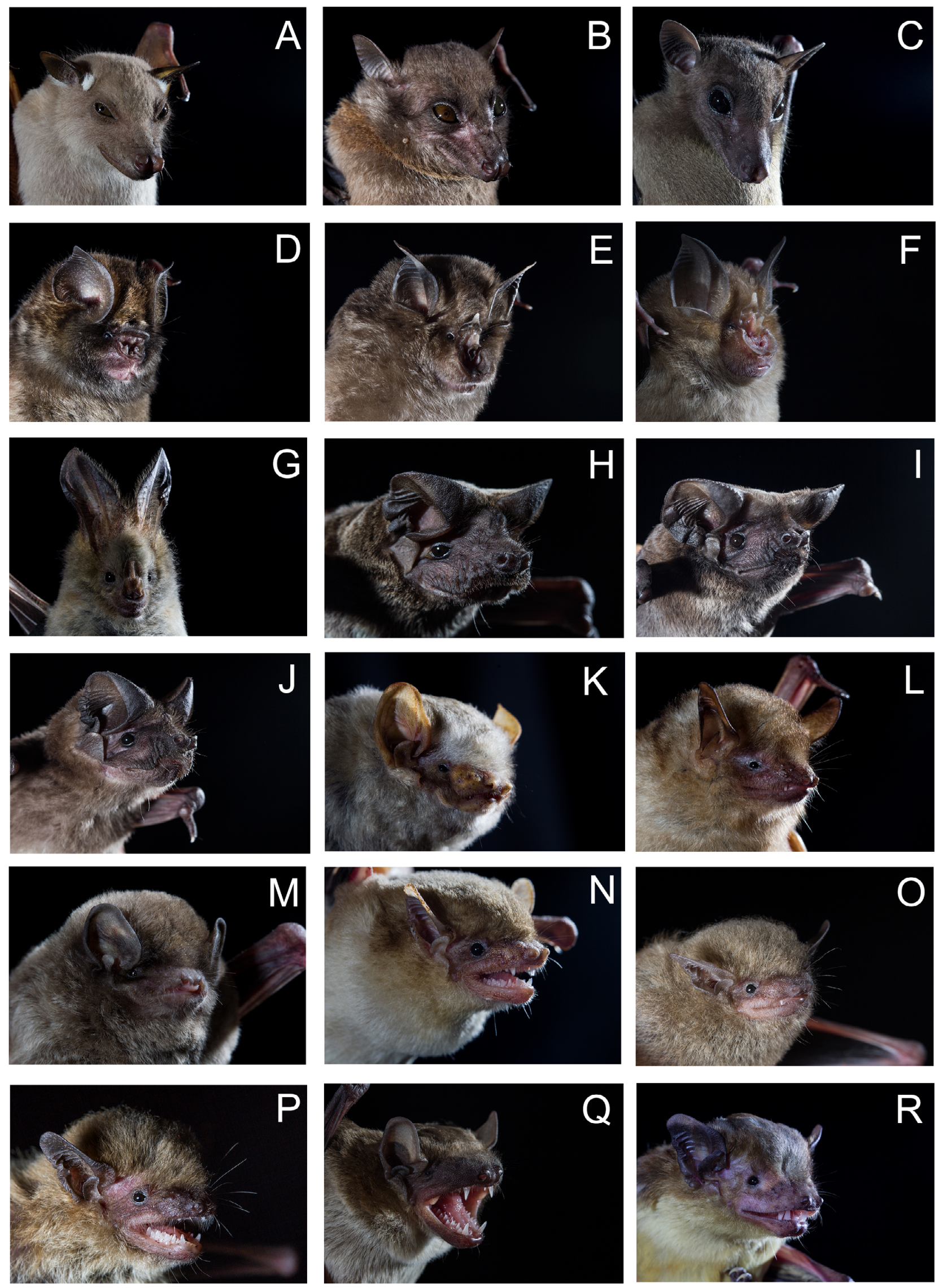

Fig. 4 - Bat species captured during this survey. A) Epomophorus wahlbergi, B) Lissonycteris angolensis, C) Rousettus aegyptiacus, D) Hipposideros caffer, E) Rhinolophus clivosus, F) Rhinolophus landeri, G) Cardioderma cor, H) Chaerephon major I) Tadarida aegyptiaca J) Chaerephon major K) Glauconycteris argentata, L) Myotis tricolor, M) Miniopterus sp., N) Nycticeinops schlieffeni, O) Pipistrellus hesperidus P) Neoromicia sp. Q) Scotoecus hirundo, R) Scotophilus dinganii 

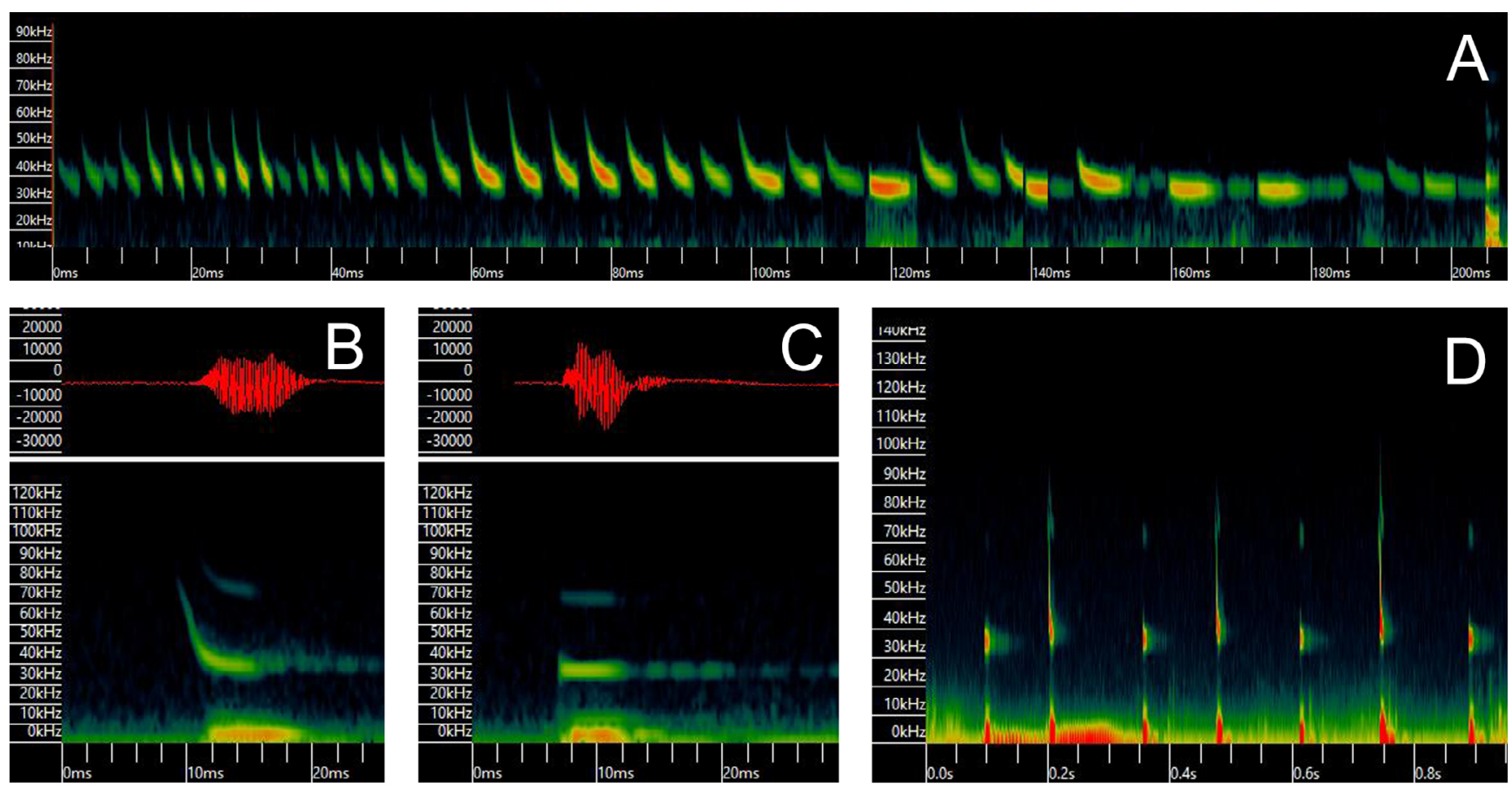

Fig. 5 - Echolocation calls of Glauconycteris argentata (A: compressed spectrogram of several pulses recorded during a commuting flight sequence; B: Zoom of a complete single pulse with the $2^{\text {nd }}$ harmonic and the initial modulated tail; C: Zoom of a complete single pulse without harmonics and only showing the quasi-constant component of the pulse and D: noncompressed commuting flight sequence.

Table 4 - Search flight call parameters for Glauconycteris argentata from our Taita Hills study area, in comparison to calls reported from Gabon (from Peerboom et al. 2012). Mean \pm SE, observed range (in parentheses).

\begin{tabular}{lll}
\hline Echolocation parameters & Taita Hills, Kenya (current study) & Gabon (Peereboom et al 2012) \\
\hline Peak Frequency $(\mathrm{kHz})$ & $40.38 \pm 1.68(36.19-44.77)$ & $43,96 \pm 1.8(40.26-47.14)$ \\
\hline Maximum Frequency $(\mathrm{kHz})$ & $56.45 \pm 9.40(41.37-75.09)$ & $89.16 \pm 7.11(77.95-101.60)$ \\
\hline Minimum Frequency $(\mathrm{kHz})$ & $35.20 \pm 3.11(16.32-40.62)$ & $31.591 .48(28.42-34.45)$ \\
\hline Bandwidth $(\mathrm{kHz})$ & $21.24 \pm 10.62(4.04-49.56)$ & \\
\hline Duration $(\mathrm{ms})$ & $4.03 \pm 1.86(0.7-8.52)$ & $2.4 \pm 0.31(2.0-3.0)$ \\
\hline Slope $(\mathrm{kHZ} / \mathrm{ms})$ & $-5.28 \pm 6.19(-48.51--0.69)$ & \\
\hline
\end{tabular}

Several colonies of Cardioderma cor and Rhinolophus spp, were found roosting in human structures (both inhabited and uninhabited) in the lowlands of the Taita Hills (Table 3). In these areas, the main vespertilionid species encountered were Pipistrellus hesperidus, Nycticeinops schlieffeni, Scotoecus hirundo, Scotophilus dinganii and Neoromicia spp.; all of them captured in open areas. In villages at higher elevations, synanthropic colonies were all composed of molossid species (e.g. Chaerephon pumilus). Molossids and other vespertilionids were also captured over open water sources (mainly Neoromicia sp. and G. argentata). Pregnancy was detected for Rousettus aegyptiacus, Epomophorus wahlbergi, $C$. pumilus and $C$. cor and lactating for $R$. aegyptiacus, C. cor and Miniopterus spp. Reproductively active male $P$. hesperidus, $R$. aegyptiacus, E. wahlbergi and C. cor, identified by a swollen scrotum, were also captured.

Echolocation calls for Glauconycteris argentata could be clearly described by a first modulated tail (concave and downward) with a large bandwidth, followed by a quasiconstant component around $40 \mathrm{kHz}$ (Table 4, Fig. 5).

\section{DiSCUSSION}

Through this bat biodiversity assessment in the Taita Hills, Kenya, we provide the first report of Miniopterus mossambicus for East Africa, as well as 10 new species records for the area, highlighting the vital importance of rapid bat fauna inventories for conservation in underexplored biodiverse regions. The focus on different habitat types and the combination of complementary trapping techniques allowed us to capture species with different detectability and foraging strategies, reinforcing the importance of diversifying the sampling methodologies (Flaquer et al. 2007, Webala et al. 2009). However, despite the high number of new species reported for the area, due to the short duration of the expedition and limited sampling effort and geographical coverage, it is unlikely that bat biodiversity is yet fully documented.

In the field, several bats were identified only to the genus level due to a lack of known diagnostic morphological characters. For some, we also found a lack of available 
matching Cyt-b reference sequences in GenBank (Table 2). Some of the most difficult specimens to identify were the Pipistrellus/Neoromicia and Miniopterus complexes. These may represent known species for which no Cyt-b sequences are available, or putative new species as $2.5 \%$ divergence has been previously used to assign new cryptic species within the Miniopterus genus(Goodman et al. 2009). To avoid further confusion, we decided to retain a genus-level classification.

For some species that we confidently identified to species level in the field, barcoding revealed inconsistencies with GenBank reference sequences. For example, although some Cyt-b sequences for Scotoecus hirundo are available in GenBank, our field samples showed $86 \%$ similarity to Pipistrellus hesperidus as the closest match. However, due to clear diagnostic external features for the males of this genus - substantially longer penis (Monadjem et al. 2010, Patterson and Webala 2012) - we favour our field identification. A similar situation occurred for Scotophilus dinganii, which was genetically similar to Scotophilus viridis but can be morphologically distinguished from it based on forearm length (longer than $51 \mathrm{~mm}$ ) (Monadjem et al. 2010, Patterson and Webala 2012). This lack of concordance may result from mistaken identity with the previous GenBank submissions or strong intra-specific geographic morphological variation invalidating current diagnostic traits.

For other species, DNA barcoding most closely matched our field identification, but showed low similarity with the available sequences (95-96\%, e.g. Hipposideros caffer and Myotis tricolor), suggesting the possibility of high genetic divergence in the Taita Hills when compared to populations elsewhere. Although the results presented here are based on only one specimen per species, this genetic divergence could be caused by isolation between the hilltops and lowlands, driven by the extreme elevational gradients in the Taita Hills (Chaverri et al. 2016). This "topographic isolation" often leads to high levels of endemism, a pattern described for several montane landscapes (Chaverri et al. 2016, Steinbauer et al. 2016).

Amongst this taxonomic uncertainty, DNA barcoding confirmed the presence of Miniopterus mossambicus captured in a river bed at low altitudes - which was only recently described to science (Monadjem et al. 2013), and represents the first record in East Africa and a significant range expansion (Monadjem et al. 2013). Our sequences for the species have a $99 \%$ match with the two available in GenBank and both the forearm length $(43 \mathrm{~mm})$ and the weight (7g) also fit the values provided by Monadjem et al. (2013). DNA barcoding also confirmed the capture of Rhinolophus clivosus, which has a severely fragmented distribution range in East Africa (Kock et al. 2008). However, the species range may be larger than currently described due to patchy research effort (Kock et al. 2008).

Synanthropy is common in some bat groups, with species in other areas reported to roost in private houses, public buildings and bridges (Amorim et al. 2013, Biavatti et al. 2015, Russo and Ancillotto 2015, López-Baucells et al. 2017). During our surveys, we identified a reproductive colony of more than 100 individuals of Chaerephon pumilus inhabiting a large cavity under the roof of a private house, and multiple Cadioderma cor colonies occupying abandoned buildings. Due to the increasing levels of forest loss across the Taita Hills landscape (Pellikka et al. 2009), these roost types will likely become increasingly important for the conservation of local bat populations as reported elsewhere (López-Baucells et al. 2017). We therefore recommend research aimed at evaluating roost selection by bats in areas facing high levels of habitat modification.

Our study provided the first Cyt-b sequence in GenBank for Glauconycteris argentata. Although widespread, this species is rarely captured. We also present the first echolocation call description for eastern Africa. The shape of its echolocation pulses corresponds to other vespertilionids species, characterized by a modulated tail and a short quasiconstant component at the end of each pulse. Compared to the only published description (from Gabon: Peerboom et al. 2012), we identified slightly lower peak frequencies of around $40 \mathrm{kHz}$, and pulses of double the duration (sometimes with only quasi-constant shapes) (Table 4). In our recording, we also report a potential pulse alternation sequence, a characteristic that has been described for other vespertilionid bats (e.g. Barbastella barbastellus) (Parsons and Jones 2000). These findings suggest that our release calls are likely to be less affected by stress imposed on the animal by handling. Upon release, this animal spent several minutes flying in a semi-open area, thus providing highquality semi-natural flying sequences. Good echolocation recordings of free flying bats under natural conditions are missing for many species (especially those inhabiting remote tropical regions) (López-Baucells et al. 2014) and are vital for creating reliable reference call libraries.

The EAM, which encompasses the Taita Hills, are a wellknown biodiversity hotspot (Badgley et al. 2017). Our study establishes that the Taita Hills are home to a rich chiropteran diversity, and highlights the importance of further research and conservation efforts in the area. Despite substantially increasing bat inventory, we failed to encounter several species that have been previously reported for the region. While this could result from low sampling effort due to the short duration of our expedition, it may also reflect a decrease in their abundance or even local extinctions. Further sampling, particularly at different times of the year, is required to evaluate this possibility. Lastly, our study further reveals the likelihood of species complexes for the region, and the need to complement species identification based on morphological traits with DNA barcoding. Because many current field guides do not provide sufficient diagnostic morphological parameters for field identification, more taxonomic research towards these hard-to-identify species is vital to improve bat surveys and monitoring in this region, and other similarly less-explored ecosystems. This would not only improve the quality of scientific outputs but is also essential for directing optimised conservation efforts.

\section{ACKNOWLEDGements}

We wish to thank our local field guide, Ben, for his assistance, and the Helsinki University Taita Research Station staff for their hospitality and logistical support. We are very grateful to Moses Masika and Bernard Agwanda for assisting with sample storage and shipping to Helsinki. We also thank the Kenya Wildlife Service for providing research 
permits to capture and collect bat specimens. This work was supported by funding from the Jenny and Antti Wihuri Foundation, Finland. ALB and RR are financially supported by the Portuguese Foundation for Science and Technology (Grants PD/BD/52597/2014 and SFRH/BD/80488/2011 respectively), and KMF is supported by the Finnish Cultural Foundation.

\section{REFERENCES}

Amorim, F., Alves, P., Rebelo, H. 2013. Bridges over the troubled conservation of Iberian bats. Barbastella, Journal of Bat Research. 6(1):3-12. http://dx.doi.org/10.14709/BarbJ.6.1.2013.01

Badgley, C., Smiley, T.M., Terry, R., Davis, E.B., DeSantis, L.R., Fox, D.L., Hopkins, S.S., Jezkova, T., MatocQ, M.D., MatzKe, N., et al. 2017. Biodiversity and Topographic Complexity: Modern and Geohistorical Perspectives. Trends Ecol Evol. 32(3):211-226. http://dx.doi.org/10.1016/j. tree.2016.12.010

Biavatti, T., Costa, L.M., EsbÉRARD, C.E. 2015. Morcegos (Mammalia, Chiroptera) em refúgios diurnos artificiais na região sudeste do Brasil. Mastozoologia Neotropical. 22(2):239-253

Britzke, E.R., Duchamp, J.E., Murray, K.L., Swihart, R.K., RobBins, L.W. 2011. Acoustic identification of bats in the eastern United States: A comparison of parametric and nonparametric methods. The Journal of Wildlife Management. 75(3):660-667. http://dx.doi.org/10.1002/jwmg.68

Brooks, T., Lens, L., De Meyer, M., Waiyaki, E., WildER, C. 1998. Avian biogeography of the Taita Hills, Kenya. Journal of East African Natural History. 87(1):189-194. http://dx.doi.org/10.2982/0012-8317(1998)87[189:ABOTT $\mathrm{H}] 2.0 . \mathrm{CO} ; 2$

Chaverri, G., Garin, I., Alberdi, A., Jimenez, L., Castillo-Salazar, C., Aihartza, J. 2016. Unveiling the Hidden Bat Diversity of a Neotropical Montane Forest. PLoS ONE. 11(10):e0162712. http://dx.doi.org/10.1371/journal. pone. 0162712

Cisneros, L.M., Burgio, K.R., Dreiss, L.M., KlingBeil, B.T., Patterson, B.D., Presley, S.J., Willig, M.R. 2014. Multiple dimensions of bat biodiversity along an extensive tropical elevational gradient. Journal of Animal Ecology. 83(5):1124-1136. http://dx.doi.org/10.1111/13652656.12201

Crochet, P.A., Chaline, O., Surget-Groba, Y., Debain, C., Cheylan, M. 2004. Speciation in mountains: phylogeography and phylogeny of the rock lizards genus Iberolacerta (Reptilia: Lacertidae). Molecular Phylogenetics and Evolution. 30(3):860-866. http://dx.doi.org/10.1016/j. ympev.2003.07.016

FJeldsÅ, J., Ehrlich, D., LAmbin, E., Prins, E. 1997. Are biodiversity 'hotspots' correlated with current ecoclimatic stability? A pilot study using the NOAA-AVHRR remote sensing data. Biodiversity and Conservation. 6(3):401-422
Flaquer, C., Torre, I., Arrizabalaga, A. 2007. Comparison of sampling methods for inventory of bat communities. Journal of Mammalogy. 88(2):526-533. https://doi. org/10.1644/06-MAMM-A-135R1.1

Goodman, S.M., Maminirina, C.P., Weyeneth, N., BraDman, H.M., Christidis, L., Ruedi, M., Appleton, B. 2009. The use of molecular and morphological characters to resolve the taxonomic identity of cryptic species: the case of Miniopterus manavi (Chiroptera, Miniopteridae). Zoologica Scripta. 38(4):339-363. http://dx.doi.org/10.1111/j.14636409.2008.00377.x

Guo, Q., Kelt, D.A., Sun, Z., Liu, H., Hu, L., Ren, H., WEN, J. 2013. Global variation in elevational diversity patterns. Sci Rep. 3:3007. http://dx.doi.org/10.1038/srep03007

Hamilton, P.B., Uren Webster, T.M., Basiewicz, M., Kennedy, E.V., De-Bastos, E.S.R., Mathews, F. 2015. A rapid PCR-based test for identification of fifteen British bat species. Conservation Genetics Resources. 7(3):651-657. http:// dx.doi.org/10.1007/s12686-015-0470-2

Irwin, D.M., Kocher, T.D., Wilson, A.C. 1991. Evolution of the cytochromeb gene of mammals. Journal of Molecular Evolution. 32(2):128-144. http://dx.doi.org/10.1007/ BF02515385

JAetzold, R., Schmidt, H. 1983. Farm Management Handbook of Kenya (Vol. II, Part C): Natural Conditions and Farm Management Information, East Kenya. ed. 573pp

Jung, K., Molinari, J., Kalko, E.K.V. 2014. Driving factors for the evolution of species-specific echolocation call design in New World free-tailed bats (Molossidae). PLoS ONE. 9(1):e85279. http://dx.doi.org/10.1371/journal. pone. 0085279

Kock, D., Amr, Z., JACOBS, D., COTTERILl, F.P.D., TAYLOR, P.J., Monadjem, A. 2008. Rhinolophus clivosus. The IUCN Red List of Threatened Species.: Downloaded on 02 March 2017. http://dx.doi.org/10.2305/IUCN.UK.2008.RLTS. T19531A8955923.en.

LAMB, J.M., NAIDOO, T., TAYLOR, P.J., NAPIER, M., RatriMOMANARIVO, F., Goodman, S.M. 2012. Genetically and geographically isolated lineages of a tropical bat (Chiroptera: Molossidae) show demographic stability over the late Pleistocene. Biological Journal of the Linnean Society. 106(1):1840. http://dx.doi.org/10.1111/j.1095-8312.2011.01853.x

Le Saout, S., Hoffmann, M., Shi, Y., Hughes, A., BerNARD, C., Brooks, T.M., BertzKy, B., Butchart, S.H.M., StUART, S.N., BADMAN, T., et al. 2013. Protected Areas and Effective Biodiversity Conservation. Science. 342(6160):803805. http://dx.doi.org/10.1126/science. 1239268

López-Baucells, A., Rocha, R., Fernández-Arellano, G., Bobrowiec, P.E.D., Palmeirim, J.M., Meyer, C.F.J. 2014. Echolocation of the big red bat Lasiurus egregius (Chiroptera: Vespertilionidae) and first record from the Central Brazilian Amazon. Studies on Neotropical Fauna and Environment. 49(1):18-25. http://dx.doi.org/10.1080/01650521.201 4.907600 
LóPez-BAucells,A., Rocha, R.,Bobrowiec,P.E.D.,BerNARd, E., PAlmeirim, J., Meyer, C. 2016. Field Guide to Amazonian Bats. ed.: INPA. Manaus.

LóPez-Baucells, A., Rocha, R., ANDriatafika, T., TojoSOA, T., Kemp, J., Forbes, K., CABeZA, M. 2017. Roost selection by synanthropic bats in rural Madagascar: what makes non-traditional structures so tempting? Hystrix. [in press]

Malcolm, J.R., Liu, C., Neilson, R.P., Hansen, L., HanNAH, L.E.E. 2006. Global Warming and Extinctions of Endemic Species from Biodiversity Hotspots. Conservation Biology. 20(2):538-548. http://dx.doi.org/10.1111/j.15231739.2006.00364.x

Millennium Ecosystem Assessment. 2005. Ecosystems and human well-being: synthesis. ed.: Island Press. Washington, DC. $155 \mathrm{pp}$

Mittermeier, R., Gil, P., Hoffmann, M., Pilgrim, J., Brooks, T., Mittermeier, C. 2004. Hotspots revisited: Earth's biologically richest and most threatened ecoregions. ed.: CEMEX. Mexico City, Mexico. 200pp

Monadjem, A., Taylor, P.J., Cotterill, W., Schoeman, M. 2010. Bats of southern and central Africa: a biogeographic and taxonomic synthesis. ed.: Wits University Press Johannesburg. Johannesburg. 608pp

Monadjem,A.,Goodman,S.M.,Stanley,W.T.,ApPleton, B. 2013. A cryptic new species of Miniopterus from southeastern Africa based on molecular and morphological characters. Zootaxa. 3746:123-142. http://dx.doi.org/10.11646/ zootaxa.3746.1.5

Myers, N., Mittermeier, R.A., Mittermeier, C.G., DA FonsecA, G.A., Kent, J. 2000. Biodiversity hotspots for conservation priorities. Nature. 403(6772):853-858. http:// dx.doi.org/10.1038/35002501

NeWmark, W.D. 2002. Conserving biodiversity in East African forests: a study of the Eastern Arc Mountains. ed.: Springer Science \& Business Media. 200pp. http://dx.doi. org/10.1007/978-3-662-04872-6

Parsons, S., Jones, G. 2000. Acoustic identification of twelve species of echolocating bat by discriminant function analysis and artificial neural networks. Journal of Experimental Biology. 203(17):2641-2656

Patterson, B.D., Webala, P.W. 2012. Keys to the Bats (Mammalia: Chiroptera) of East Africa. Fieldiana Life and Earth Sciences.1-60. http://dx.doi.org/10.3158/2158-552012.6.1

Peerboom, D., Van Lieshout, S., Jeffery, K.J., BergMANS, W. 2012. First record and echolocation call of Glauconycteris argentata (Dobson, 1875) from Gabon. African Bat Conservation News. 27(1):3-5

PellikKa, P.K.E., Lötjönen, M., Siljander, M., Lens, L. 2009. Airborne remote sensing of spatiotemporal change (1955-2004) in indigenous and exotic forest cover in the Taita Hills, Kenya. International Journal of Applied Earth Observation and Geoinformation. 11(4):221-232. http://dx.doi. org/10.1016/j.jag.2009.02.002
Peters, M.K., Hemp, A., Appelhans, T., Behler, C., Classen, A., Detsch, F., Ensslin, A., Ferger, S.W., FrederikSEn, S.B., Gebert, F. 2016. Predictors of elevational biodiversity gradients change from single taxa to the multi-taxa community level. Nature Communications. 7. http://dx.doi. org/10.1038/ncomms 13736

Presley, S.J., Cisneros, L.M., Patterson, B.D., WilLIG, M.R. 2012. Vertebrate metacommunity structure along an extensive elevational gradient in the tropics: a comparison of bats, rodents and birds. Global Ecology and Biogeography. 21(10):968-976. http://dx.doi.org/10.1111/j.14668238.2011.00738.x

Republic of Kenya. 2001. The 1999 Population \& Housing Census. . ed.: Central Bureau of Statistics, Ministry of Planning and National Development. Nairobi, Kenya.

Russo, D., Ancillotto, L. 2015. Sensitivity of bats to urbanization: a review. Mammalian Biology. 80(3):205-212. http://dx.doi.org/10.1016/j.mambio.2014.10.003

Simmons, N.B. 2005. Order chiroptera. In: Mammal species of the world: a taxonomic and geographic reference. ed. Johns Hopkins University Press Baltimore. Maryland. p. 312-529

Steinbauer, M.J., Field, R., Grytnes, J.-A., Trigas, P., Ah-Peng, C., Attorre, F., Birks, H.J.B., Borges, P.A.V., CArdoso, P., CHOU, C.-H., et al. 2016. Topography-driven isolation, speciation and a global increase of endemism with elevation. Global Ecology and Biogeography. 25(9):10971107. http://dx.doi.org/10.1111/geb.12469

Taylor, P.J., Geiselman, Cullen., Kabochi, Paul, AgWANDA, B., TURNER, S. 2005. Intraspecific variation in the calls of some African bats (Order Chiroptera). Durban Museum Novitates. 30(1):24-37

Thiss, K.W., Roelen, I., Musila, W.M. 2014. Field Guide to the Woody Plants of Taita Hills, Kenya. Journal of East African Natural History. 102(1-2):1-272

Voigt, C.C., Holderied, M.W. 2012. High manoeuvring costs force narrow-winged molossid bats to forage in open space. Journal of Comparative Physiology B-Biochemical Systemic and Environmental Physiology. 182(3):415-424. http://dx.doi.org/10.1007/s00360-011-0627-6

Wagura, L. 2014. A guide to Taita Hills unique natural history. ed.: National Museum of Kenya. Nairobi, Kenya. $74 \mathrm{pp}$

Webala, P., Carugati, C., Canova, L., Fasola, M. 2009. Bat assemblages from eastern lake turkana, Kenya. Revue d'écologie. 64(1):85-91 


\section{SUPPLEMENTARY MATERIAL}

Table 1 - Accession numbers for all sequences deposited in GenBank.

\begin{tabular}{cl}
\hline Accession numbers & Species \\
\hline KY864367 & Scotoecus cf. hirundo \\
\hline KY864368 & Scotoecus cf. hirundo \\
\hline KY864369 & Hipposideros caffer \\
\hline KY864370 & Pipistrellus hesperidus \\
\hline KY864371 & Myotis tricolor \\
\hline KY864372 & Glauconycteris argentata \\
\hline KY864373 & Miniopterus sp. \\
\hline KY864374 & Rhinolophus clivosus \\
\hline KY864375 & Pipistrellus hesperidus \\
\hline KY864376 & Miniopterus sp. \\
\hline KY864377 & Pipistrellus hesperidus \\
\hline KY864378 & Rhinolophus clivosus \\
\hline KY864379 & Scotophilus sp. \\
\hline KY864380 & Scotoecus cf. hirundo \\
\hline KY864381 & Neoromicia nana \\
\hline KY864382 & Scotoecus cf. hirundo \\
\hline KY864383 & Scotophilus sp. \\
\hline KY864384 & Miniopterus mossambicus \\
\hline KY864385 & Miniopterus sp. \\
\hline KY864386 & Neoromicia nana \\
\hline KY864387 & Scotoecus cf. hirundo \\
\hline KY864388 & Neoromicia sp. \\
\hline KY864389 & Neoromicia sp. \\
\hline
\end{tabular}

